\title{
Supraclavicular Artery Flap - A promising versatile Flap: An early Experience
}

\author{
${ }^{1}$ Deepak Janardhan, ${ }^{2}$ Shaji Thomas, ${ }^{3}$ Sharath K Krishnan, ${ }^{4}$ Philip J Kottaram
}

\begin{abstract}
Introduction: Reconstruction of major head and neck defects remains challenging for head and neck surgeons. As esthetic expectations are extremely demanding, in terms of colormatch, texture and functional dexterity. Reconstructive options range widely from skin grafts tolocoregional or even free flaps. The need of the hour would be a versatile flap that harbours only the desired characteristics of both local and free flaps.
\end{abstract}

Materials and methods: Patients requiring local flap reconstruction after excision of the head and neck malignant lesion in our department, were included in the study after informed consent.

Results: Two patients had reconstruction of the extended radical parotidectomy skin defect and one patient had intraoral defect post oncological resection, which were reconstructed with supraclavicular artery flap.

Conclusion: The early experience of using supraclavicular artery flap in three cases of head and neck reconstruction following oncological resection is highly gratifying.

Keywords: Head and neck, Locoregional flap, Oncology, Supraclavicular flap.

How to cite this article: Janardhan D, Thomas S, Krishnan SK, Kottaram PJ. Supraclavicular Artery Flap - A promising versatile Flap: An early Experience. Int J Head Neck Surg 2016;7(4):228-230.

Source of support: Nil

Conflict of interest: None

\section{INTRODUCTION}

Head and neck oncologic resections are usually complex to reconstruct. Resurfacing such defects can be done with locoregional flaps or free flaps. Regional flaps like the pectoralis major myocutaneous flap, the main workhorse in high-volume centers like ours, are bulky, making it difficult to handle and tend to leave donor site morbidity. The other end of the spectrum would be microvascular free flaps that require expertise, increased operative time, and constant monitoring in the postoperative period. In this scenario, supraclavicular artery flap (SCAF) tends to be a promising option due to its ease in harvesting and

\footnotetext{
${ }^{1,4}$ Fellow, ${ }^{2}$ Additional Professor, ${ }^{3}$ Trainee

${ }^{1-4}$ Department of Surgical Oncology, Regional Cancer Centre Thiruvananthapuram, Kerala, India

Corresponding Author: Deepak Janardhan, Fellow Department of Surgical Oncology, Regional Cancer Centre Thiruvananthapuram, Kerala, India, Phone: +919961319859 e-mail: dr.deepakjanardhan@gmail.com
}

minimal learning curve involved, like a locoregional flap. Also, its thin, pliable nature with good color match ranks it at par with results of microvascular free flaps, which is the standard of care today.

\section{MATERIALS AND METHODS}

Patients at our institution, Regional Cancer Centre, were considered for SCAF reconstruction with informed consent if their defect was not expected to close primarily and was expected to require a regional flap, provided level 5 neck node dissection was not mandatory. Due to the initial learning curve, its utility in outer skin defect was explored first and then used intraorally.

\section{TECHNIQUE}

The flap design (Fig. 1) is centered over deltoacromial prominence after marking the triangle formed by posterior border of sternomastoid muscle, external jugular vein, and adjacent clavicle, pointing the origin of perforator coursing toward acromion and beyond. We had not used hand-held Doppler to identify the perforator as advocated by some authors. The flap is raised in a subfascial plane from distal to proximal direction and once at nodal levels 4 and 5 care is taken not to disturb the transverse cervical artery and the perforator. The reach is assessed with respect to the pivot point and tunneled under the superior neck skin flap after deepithelializing the corresponding segment, which is the time-consuming part of flap harvesting. The donor site is then closed primarily

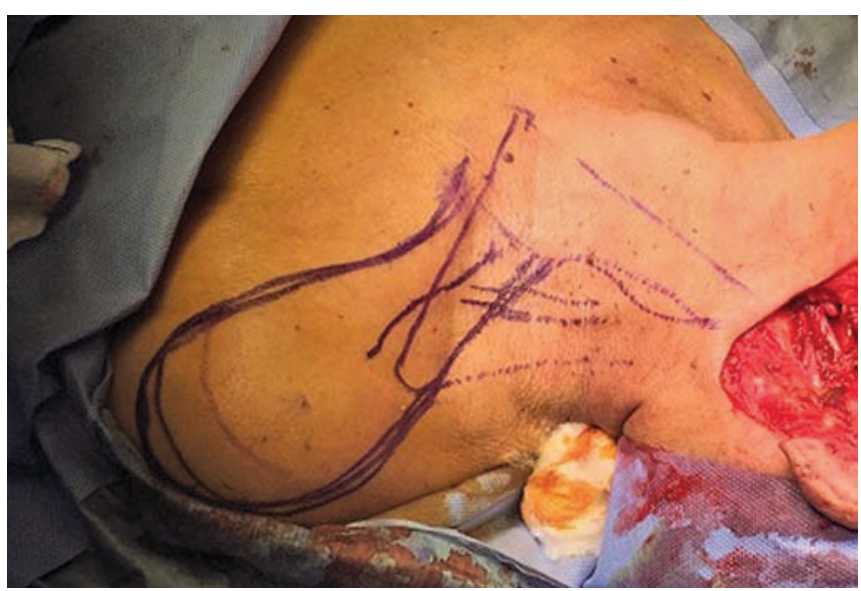

Fig. 1: The flap design with triangle formed by posterior border of sternomastoid muscle, external jugular vein and clavicle, showing the point of perforator origin 


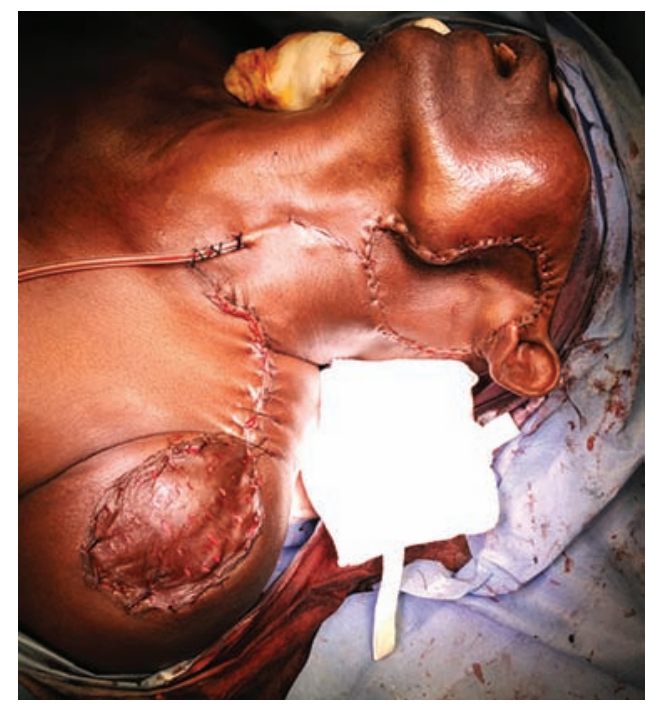

Fig. 2: Folllowing extended radical parotidectomy, skin defect reconstructed with supraclavicular flap and donor site skin grafted

whenever possible or a small skin graft may be used; with neck drain, after the flap is inset. Stretch tension coupled with the rotation at the base and maybe to some extent tunneling compromises the vascularity.

\section{CASE REPORTS}

\section{Case 1}

A 55-year-old male was diagnosed with recurrent highgrade mucoepidermoid parotid carcinoma with facial palsy and skin infiltration. He underwent extended radical parotidectomy with flap reconstruction (Fig. 2).

\section{Case 2}

An 80-year-old male was diagnosed with carcinoma of lower alveolus. He underwent wide excision of the lesion with hemimandibulectomy and neck dissection with SCAF reconstruction (Fig. 3).

\section{Case 3}

A 75-year-old diabetic female was diagnosed as poorly differentiated parotid carcinoma with skin infiltration. She underwent extended radical parotidectomy with SCAF reconstruction (Fig. 4).

\section{RESULTS}

The learning curve for harvesting the flap is nil. Our mean flap dimensions were $10.16(8.5-13) \mathrm{cm}$ in width and $19.5(15-26) \mathrm{cm}$ in length. The average duration of harvesting the flap was 47 minutes. Case 1 required donor site skin grafting, as the flap design had to be extended till angiosome 3 and closing the defect primarily would have resulted in limited shoulder mobility. Special attention was given to avoid hypotension in intra-operative and immediate postoperative periods

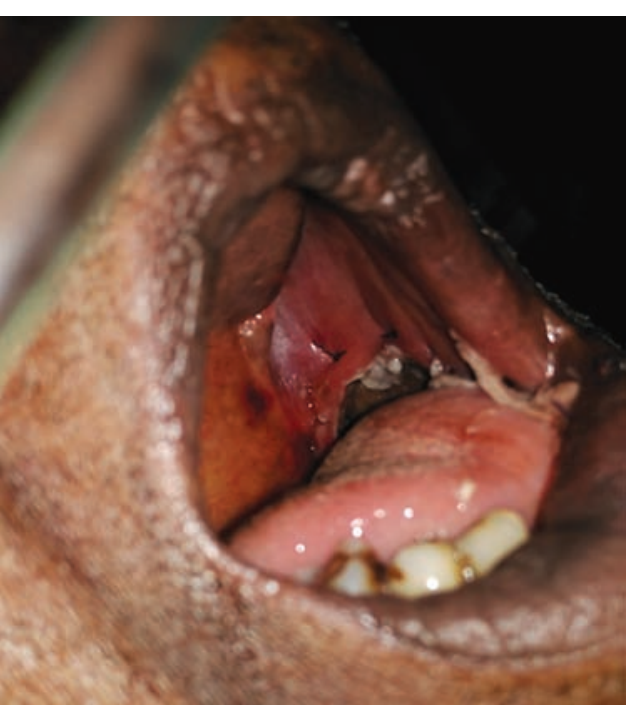

Fig. 3: Post hemimandibulectomy intraoral mucosal defect reconstructed with supraclavicular flap

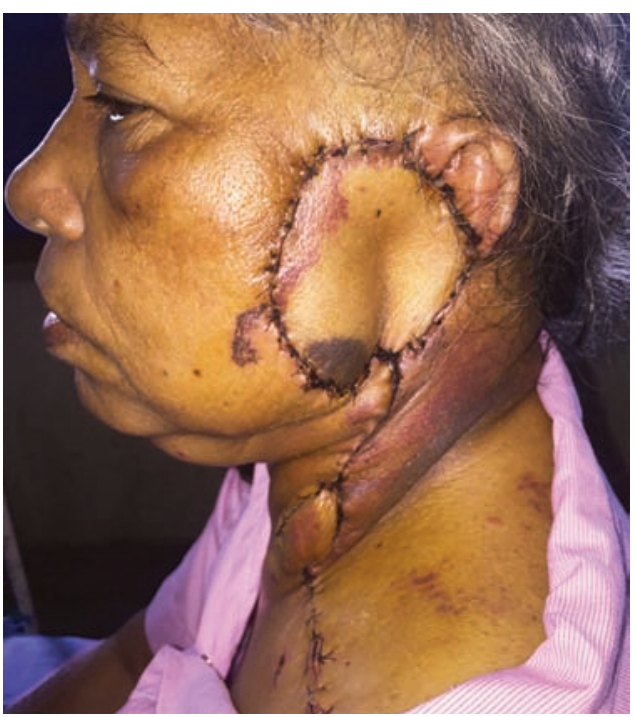

Fig. 4: Post extended radical parotidectomy, facial skin reconstructed with supraclavicular flap

with adequate antibiotic coverage. All the cases were followed up for more than 3 months. Case 3 had a $5 \mathrm{~mm}$ area edge necrosis that was noted as discoloration from postoperative day 3, had delayed secondary healing. All the patients were satisfied with the results.

\section{DISCUSSION}

Supraclavicular artery flap is an axial pattern, fasciocutaneous flap based on SCA, a perforator from transverse cervical artery $(90 \%)$ and rarely from suprascapular artery $(10 \%)$. History of introduction of SCAF dates way back to 1842 when Mutter described a random pattern flap of the supraclavicular area. ${ }^{1}$ Kazanjian and Converse publicized it as "in charretera" or acromial flap ${ }^{2}$ in 1949. The same was described as the Demergasso flap ${ }^{3}$ by Mathes and Nahai. ${ }^{4-6}$ The first anatomical studies of the cervicohumeral flap were performed in 1978 
by Mathes, Vasconez and Wilson. ${ }^{78}$ In 1983, Cormack and Lamberty ${ }^{9,10}$ described the vascular anatomy and defined the flap as a laterally extended cervicohumeral. Lamberty and Cormack ${ }^{11}$ identified the perforator that arose from the transverse cervical artery in $93 \%$ of cases or from the suprascapular artery in $7 \%$ of cases and named it as supraclavicular artery in 1979. In 1997, Pallua et al ${ }^{12}$ described the supraclavicular island flap for releasing postburn mentosternal contractures and for long been used for treating postburn contractures until Chiu et al ${ }^{13}$ rediscovered its utility in oncological reconstruction. Modifications have been made to optimize and expand in the supraclavicular artery angiosome of the anterior shoulder so as to allow the flap to cover larger defects.

Surface marker of origin of the supraclavicular artery perforator is located in the triangle created by the external jugular vein, the posterior border of the sternocleidomastoid muscle, and the clavicle. Studies have shown that the origin of the perforator corresponds to mid- one-third clavicle in 33 to $90 \%$ and lateral one-third in 10 to $44 \%$, approximately $2 \mathrm{~cm}$ from the clavicle. ${ }^{14,15}$ A flap design that is 10 to $16 \mathrm{~cm}$ wide and 22 to $30 \mathrm{~cm}$ long has been confirmed to be safe and reliable with dye injection studies and identification of angiosome. ${ }^{16-18}$

Absence of the need to isolate the pedicle makes it easy to harvest. The arc of rotation on the base of the neck provides adequate length to reach up to upper third of the face, and using it for intraoral, pharyngeal, and facial skin defects. ${ }^{17}$ The only drawback limiting its utility in an oncological setting would be situations where level 5 nodal clearance is warranted. Reported donor site complications with the supraclavicular artery island flap are minor wound dehiscence, tightness in the shoulder, minimal widening of the donor site scar..$^{19}$ Literature reveals reports of referred sensation to the shoulder when drinking hot or cold beverages, when used for pharyngeal reconstruction. ${ }^{16}$ This has been attributed to the middle supraclavicular nerve, probably making it a sensate flap.

\section{CONCLUSION}

Supraclavicular artery flap is a safe and reliable reconstructive option for selected defects of the head and neck region. It is an ideal alternative for free flaps for reconstruction of selected case scenarios, in a high-volume oncology center as ours, considering the minimal learning curve involved, ease in harvesting, and reliability.

\section{REFERENCES}

1. Gillies HD. The tubed pedicle in plastic surgery. J Laryngol Otol 1923 Sep;38(9):503-503.

2. Kazanjian, VH.; Converse, JM. The surgical treatment of facial injuries. Baltimore (MD): Williams and Wilkins; 1949.

3. Demergasso F, Piazza MV. Trapezius myocutaneous flap in reconstructive surgery for head and neck cancer: an original technique. Am J Surg 1979 Oct;138(4):533-536.

4. Mathes, SJ.; Nahai, F. Clinical atlas of muscle and musculocutaneous flaps. St. Louis: Mosby; 1979.

5. Mathes, SJ.; Nahai, F. Clinical applications for muscle and musculocutaneous flaps. St. Louis: Mosby; 1982.

6. Mathes, SJ.; Nahai, F. Reconstructive surgery: principles, anatomy and technique. New York: Churchill Livingstone; 1997. p. 10-12.

7. Mathes SJ, Vasconez LO. The cervico-humeral flap. Plast Reconstr Surg 1978 Jan;61(1):7-12.

8. Wilson CA. The cervicohumeral flap (Letter). Plast Reconstr Surg 1978 Aug;62(2):288.

9. Cormack GC, Lamberty BGH. The anatomical vascular basis of the axillary fasciocutaneous pedicle flap. Br J Plast Surg 1983 Nov;36(4):425-427.

10. Cormack GC, Lamberty BG. A classification of fasciocutaneous flaps according to their patterns of vascularization. Br J Plast Surg 1984 Jan;37(1):80-87.

11. Lamberty BG, Cormack GC. Misconceptions regarding the cervicohumeral flap. Br J Plast Surg 1983 Jan;36(1):60-63.

12. Pallua N, Machens HG, Rennekampff O, Becker $M$, Berger $\mathrm{A}$. The fasciocutaneous supraclavicular artery island flap for releasing postburn mentosternal contractures. Plast Reconstr Surg 1997 Jun;99(7):1878-1884.

13. Chiu ES, Liu PH, Friedlander PL. Supraclavicular artery island flap for head and neck oncologic reconstruction: indications, complications, and outcomes. Plast Reconstr Surg 2009 Jul;124(1):115-123.

14. Vinh VQ, Ogawa R, Van Anh T, Hyakusoku H. Reconstruction of neck scar contractures using supraclavicular flaps: retrospective study of 30 cases. Plast Reconstr Surg 2007 Jan;119(1): 130-135.

15. Tayfur V, Magden O, Edizer M, Menderes A. Supraclavicular artery flap. J Craniofac Surg 2010 Nov;21(6):1938-1940.

16. Sandu K, Monnier P, Pasche P. Supraclavicular flap in head and neck reconstruction: experience in 50 consecutive patients. Eur Arch Otorhinolaryngol 2012 Apr;269(4):1261-1267.

17. Alves HRN, Ishida LC, Ishida LH, Besteiro JM, Gemperli R, Faria JC, Ferreira MC. A clinical experience of the supraclavicular flap used to reconstruct head and neck defects in late-stage cancer patients. J Plast Reconstr Aesthet Surg 2012 Oct;65(10):1350-1356.

18. Chen WL, Zhang DM, Yang ZH, Huang ZQ, Wang JG, Zhang B, Li JS. Extended supraclavicular fasciocutaneous island flap based on the transverse cervical artery for head and neck reconstruction after cancer ablation. J Oral Maxillofac Surg 2010 Oct;68(10):2422-2430.

19. Kokot N, Mazhar K, Reder LS, Peng GL, Sinha UK. The supraclavicular artery island flap in head and neck reconstruction: applications and limitations. JAMA Otolaryngol Head Neck Surg 2013 Nov;139(11):1247-1255. 